Published in final edited form as:

Microbes Infect. 2016 January ; 18(1): 21-29. doi:10.1016/j.micinf.2015.08.015.

\title{
Role of the Yersinia YopJ protein in suppressing Interleukin-8 secretion by human polymorphonuclear leukocytes
}

\author{
Justin L. Spinnera ${ }^{\mathrm{a}}$, Aaron M. Hasenkrug ${ }^{\mathrm{a}}$, Jeffrey G. Shannon ${ }^{\mathrm{a}}$, Scott D. Kobayashi ${ }^{\mathrm{b}}$, and B. \\ Joseph Hinnebusch ${ }^{\mathrm{a},{ }^{*}}$ \\ aLaboratory of Zoonotic Pathogens, Rocky Mountain Laboratories, National Institute of Allergy \\ and Infectious Diseases, National Institutes of Health, 905 S. $4^{\text {th }}$ St. Hamilton, Montana 59840 \\ USA
}

bLaboratory of Human Bacterial Pathogenesis, Rocky Mountain Laboratories, National Institute of Allergy and Infectious Diseases, National Institutes of Health, 905 S. $4^{\text {th }}$ St. Hamilton, Montana 59840 USA

\section{Abstract}

Polymorphonuclear leukocytes, in addition to their direct bactericidal activities, produce cytokines involved in the activation and regulation of the innate and adaptive immune response to infection. In this study we evaluated the cytokine response of human PMNs following incubation with the pathogenic Yersinia species. Y. pestis strains with the pCD1 virulence plasmid, which encodes cytotoxic Yop proteins that are translocated into host cells, stimulated little or no cytokine production compared to pCD1-negative strains. In particular, PMNs incubated with pCD1negative $Y$. pestis secreted 1,000-fold higher levels of interleukin-8 (IL-8 or CXCL8), a proinflammatory chemokine important for PMN recruitment and activation. Deletion of yopE, $-H$, $-T,-M$ or $y p k A$ had no effect on $\mathrm{PCD} 1-$ dependent inhibition, whereas deletion of yopJ resulted in significantly increased IL-8 production. Like $Y$. pestis, the enteropathogenic Yersinia species inhibited IL-8 secretion by PMNs, and strains lacking the virulence plasmid induced high levels of IL-8. Our results show that virulence plasmid-encoded effector Yops, particularly YopJ, prevent IL-8 secretion by human PMNs. Suppression of the chemotactic IL-8 response by $Y$. pestis may contribute to the delayed PMN recruitment to the infected lymph node that typifies bubonic plague.

\section{Keywords}

Neutrophil; IL-8; CXCL8; YopJ; Yersinia; Plague

*Corresponding author: B. Joseph Hinnebusch (jhinnebusch@niaid.nih.gov), 905 S. $4^{\text {th }}$ St., Hamilton, MT 59840 USA, Tele: 406-363-9260; Fax 406-375-9681.

Present address: GlaxoSmithKline, 553 Old Corvallis Road, Hamilton MT 59840 (J. L. S.); New York Medical College, Valhalla, NY 10595 (A. M. H.)

Publisher's Disclaimer: This is a PDF file of an unedited manuscript that has been accepted for publication. As a service to our customers we are providing this early version of the manuscript. The manuscript will undergo copyediting, typesetting, and review of the resulting proof before it is published in its final citable form. Please note that during the production process errors may be discovered which could affect the content, and all legal disclaimers that apply to the journal pertain.

Conflict of Interest

The authors declare no conflict of interest. 


\section{Introduction}

Polymorphonuclear leukocytes (neutrophils or PMNs) are the most abundant circulating white blood cell of humans. PMNs are recruited to sites of infection and tissue damage by chemotactic molecules, such as $\mathrm{N}$-formyl peptides, complement components, interleukin-8 (IL-8) and lipopolysaccharide (LPS) [1]. Recruited PMNs rapidly ingest microbes by a process known as phagocytosis and kill internalized organisms by releasing highly microbicidal reactive oxygen species (ROS) and potent antimicrobial components into the pathogen-containing vacuoles [1]. PMNs also secrete a number of cytokines, chemokines, and other effector molecules important in mediating inflammation [2,3]. Thus, PMNs are not only important for the elimination of pathogens through direct killing mechanisms but are also integrated in the activation and regulation of both the innate and adaptive immune systems [2,3]. In order to persist within the mammalian host and cause disease, pathogens likely make use of mechanisms that disrupt these broader immune functions of PMNs in addition to mechanisms that confer resistance to phagocytosis and killing.

The genus Yersinia includes three species pathogenic to humans. Y. enterocolitica and $Y$. pseudotuberculosis are transmitted by the fecal-oral route and usually cause self-limited mesenteric lymphadenitis and gastroenteritis. $Y$. pestis is typically transmitted through the bite of an infected flea or through exposure of open wounds to infected material and causes bubonic and septicemic plague. Y. pestis can also be transmitted through inhalation of aerosolized droplets containing $Y$. pestis, resulting in an uncommon but highly lethal pneumonic form of plague. All three pathogenic Yersinia species maintain a virulence plasmid necessary for pathogenesis, termed $\mathrm{pCD} 1$ in $Y$. pestis and $\mathrm{pYV}$ in the enteropathogenic Yersinia. The virulence plasmid encodes a type III secretion system (T3SS) that translocates six Yersinia effector proteins, termed YopE, -H, -T, -J (YopP in $Y$. enterocolitica), -M, and YpkA (YopO in Y. enterocolitica), into host cells. Once within the target cell, each of the effector Yops target different signaling molecules and function collectively to counteract multiple signaling responses in the infected host cell [4].

In murine models of bubonic plague, injection of $Y$. pestis into the dermis results in a rapid influx of large numbers of PMNs that surround and interact with the bacteria at the injection site [5]. Nevertheless, wild-type $Y$. pestis disseminates to the draining lymph node and multiplies to produce the bubonic stage of plague without stimulating a strong PMN response to that site [6-10]. In contrast, dissemination of pCD1-negative Y. pestis is accompanied by the influx of large numbers of PMNs to the lymph node, where the bacteria are eliminated without further spread $[8,10]$. Studies comparing the host response to virulence plasmid-positive and virulence plasmid-negative $Y$. pestis have in general demonstrated a virulence plasmid-dependent inhibition of certain proinflammatory cytokine responses [8,11-13]. A proposed role has been described for each individual Yop, except Ypka/YopO, in inhibition of cytokine production by a variety of cell types [4]. However, the cytokine response of human PMNs to Y. pestis and the enteropathogenic Yersinia has not been thoroughly investigated and is explored herein. The contribution of virulence plasmidencoded factors, particularly the effector Yops, in alteration of cytokine production by human PMNs is also described. 


\section{Materials and Methods}

\subsection{Bacterial strains, plasmids and culture conditions}

Strains and plasmids used are listed in Table I. Only attenuated $Y$. pestis strains which lack the Pgm locus (KIM5 and KIM6) or the pCD1 virulence plasmid (KIM6+ and KIM6) and are excluded from CDC Category A Select Agent regulations were used. KIM5 $\Delta y p k A$ and KIM5 $\triangle y o p E,-H,-T$ and $-M$ gene deletion strains were created using the lambda red recombinase-mediated knockout procedure system as described [14]. Gene deletion cassettes were generated by PCR using primers listed in Table 2. Gene deletions were verified by PCR. The yopJ deletion and the substitution of $Y$. pestis yopJ for $Y$. enterocolitica yopP (KIM5 yopJ-yopP) have been described [15].

The low-copy YopJ-complementation plasmid pWKS::yopJ was created by cloning the PCR-amplified YopJ open reading frame flanked by $\sim 400 \mathrm{bp}$ of upstream and downstream sequence into the low-copy plasmid pWKS130 using the $S a c \mathrm{I}$ and $\mathrm{XbaI}$ restriction sites. The YopJ amplicon was also cloned directly into the high-copy plasmid pCR-XL-TOPO using a TOPO TA Cloning Kit (Life Technologies, Grand Island, NY). PCR primers used to amplify the yopJ cassette are listed in Table 2.

Yersinia were grown in brain heart infusion (BHI) broth, supplemented with $2.5 \mathrm{mM} \mathrm{CaCl}_{2}$, with aeration at $21^{\circ} \mathrm{C}$ overnight from frozen stocks. Cultures were transferred to $37{ }^{\circ} \mathrm{C}$ for 2 $\mathrm{h}$ prior to each assay to induce expression of the T3SS and effector Yop proteins. Escherichia coli was grown in Luria-Bertani (LB) broth with aeration at $37{ }^{\circ} \mathrm{C}$ overnight from frozen stocks. Where appropriate, kanamycin $(50 \mu \mathrm{g} / \mathrm{mL})$, chloramphenicol (10 $\mu \mathrm{g} / \mathrm{mL})$ or streptomycin $(50 \mu \mathrm{g} / \mathrm{mL})$ was added to the broth cultures at the indicated final concentration. Bacteria were washed in Dulbecco's phosphate-buffered saline (DPBS, Life Technologies, Grand Island, NY) and resuspended in RPMI 1640 medium with $10 \mathrm{mM}$ HEPES (RPMI, Life Technologies). To prepare opsonized Y. pestis and E. coli, bacteria were resuspended in $20 \%$ autologous normal human serum (NHS) for $30 \mathrm{~min}$ at $37^{\circ} \mathrm{C}$, washed in DPBS and resuspended in RPMI. Heat-inactivation of $Y$. pestis was done at $56{ }^{\circ} \mathrm{C}$ for $1 \mathrm{~h}$. Bacteria were enumerated by Petroff-Hauser direct count and adjusted to the desired concentration. Virulence plasmid retention was assessed by PCR or plating cultures on lowcalcium Congo red-magnesium oxalate agar (CRMOX, $20 \mathrm{mM}$ Na oxalate, $20 \mathrm{mM} \mathrm{MgCl}$ ) [16] and incubation at $37^{\circ} \mathrm{C}$ for two days.

\subsection{Preparation and use of human PMNs}

Human heparinized blood was obtained from healthy individuals in accordance with a protocol approved by the Institutional Review Board for Human Subjects of NIAID. Donors were informed of the procedure risks and provided written consent prior to enrollment. Human PMNs were purified from heparinized venous blood as described [17] and preparations contained less than $1 \%$ contaminating lymphocytes.

PMNs $\left(2 \times 10^{5}\right)$ suspended in RPMI were added to serum-coated wells (20\% NHS for 30 min at $\left.37^{\circ} \mathrm{C}\right)$ of a 96-well tissue culture plate. Bacteria were then added (5:1 bacteria-toPMN ratio); replicate wells containing uninfected PMNs or media alone served as controls. Plates were incubated at $37^{\circ} \mathrm{C}, 5 \% \mathrm{CO}_{2}$. For experiments where two strains of bacteria were 
added to a single well, each strain was added at a 2.5:1 bacterium-to-PMN ratio to yield a final bacteria-to-PMN ratio of 5:1. The first strain was added and allowed to incubate with PMNs for 30 min prior to the addition of the second strain. The final volume per well, in all experiments, was $200 \mu \mathrm{L}$. For all experiments, after $4 \mathrm{~h}$ of incubation at $37^{\circ} \mathrm{C}, 5 \% \mathrm{CO}_{2}$, gentamicin (Sigma, Saint Louis, MO) $(2.5 \mu \mathrm{g} / \mathrm{mL})$ was added and left for the remainder of the assay to limit growth of extracellular bacteria. Plates were incubated at $37{ }^{\circ} \mathrm{C}, 5 \% \mathrm{CO}_{2}$ for a total of $12 \mathrm{~h}$ or $24 \mathrm{~h}$.

\subsection{Secretion of cytokines and chemokines by PMNs}

At the indicated time point, plates were centrifuged at $400 \times \mathrm{g}$ for $10 \mathrm{~min}$. Culture supernatants were then transferred into microcentrifuge tubes and centrifuged at $13,000 \times \mathrm{g}$ for $10 \mathrm{~min}$ to pellet any remaining cells. Supernatants were collected and stored at $-80{ }^{\circ} \mathrm{C}$ prior to analysis. Levels of IL-8 (CXCL8), G-CSF, GM-CSF, MIP-1a (CCL3), MIP-1 $\beta$ (CCL4), IL-1 $\beta$, IL-1ra, IL-6, IL-12, MCP-1 (MCAF, CCL2), IL-17 and TNF-a in the supernatant of each sample were simultaneously determined using a Bio-Plex Pro human cytokine assay plate and a Bio-Plex 200 System controlled by Bio-Plex Manager 4.1.1 (BioRad Laboratories, Hercules, CA). Alternatively, levels of IL-8 in culture supernatants were analyzed by ELISA (Legend Max ELISA Kit, BioLegend Inc., San Diego, CA). With a few exceptions noted in the figure legends, experiments were performed in triplicate at least three times. Data were analyzed by one-way ANOVA with Tukey post-test using GraphPad Prism version 6.01 for Windows (GraphPad Software, San Diego, CA).

\section{Results}

\subsection{Cytokine response of human PMNs following exposure to $Y$. pestis}

As an initial screen to assess the cytokine response of human PMNs following exposure to $Y$. pestis, the levels of twelve cytokines/chemokines/growth factors (hereafter collectively referred to as cytokines) were measured in culture supernatants recovered $12 \mathrm{~h}$ or $24 \mathrm{~h}$ after addition of bacteria, using BioPlex multiplex immunoassay instrumentation. These twelve were chosen based on previous evidence that they can be produced by PMNs upon recognition of bacteria or bacteria-derived factors such as LPS [2,3]. E. coli and Y. pestis lacking the pCD1 virulence plasmid (KIM6) stimulated the secretion of several cytokines above the background levels observed from uninfected PMNs (Fig. 1). Three of them, the chemokine IL-8 and the cytokines IL-1 $\beta$ and IL-1 receptor antagonist (IL-1ra) were consistently detected at elevated levels from all PMN donor samples at both $12 \mathrm{~h}$ and $24 \mathrm{~h}$ after infection with KIM6. By far the most pronounced response was IL-8 secretion, present at concentrations greater than $1 \times 10^{4} \mathrm{pg} / \mathrm{mL}$, with IL- $1 \beta$ and IL-1ra present at concentrations approximately one hundred-fold less than IL-8 (Fig. 1).

In contrast to $Y$. pestis KIM6 and $E$. coli, $\mathrm{PMNs}$ incubated with pCD1 ${ }^{+} Y$. pestis (KIM5) secreted less of nearly all cytokines tested (Fig. 1). Most prominently, PMNs incubated with KIM5 secreted 1,000-fold less IL-8 than PMNs incubated with the pCD1- KIM6. KIM5 strains that were lacking one of the pCD1-encoded yopE, yopH, yopT, yopM or ypkA T3SS effector genes were all able to inhibit secretion of IL-8 as well as the parental KIM5 (Fig. 1). In contrast, KIM5 $\Delta y o p J$, the strain deleted of the pCD1-encoded YopJ effector protein gene, 
was only partially able to inhibit secretion of IL-8. Levels of some other cytokines secreted following incubation with KIM5 $\triangle$ yopJ were greater than PMNs incubated with KIM5, but were similar to or slightly less than PMNs incubated with KIM6 or E. coli. In particular, at $12 \mathrm{~h}$, the amount of IL-8 secreted by PMNs incubated with KIM5 $5 y o p J$ was approximately 100-fold greater than that of PMNs incubated with KIM5, but approximately 10-fold less than that of PMNs incubated with KIM6 (Fig. 1). This indicates that the pCD1 virulence plasmid encodes factors able to inhibit cytokines secreted by PMNs in response to $Y$. pestis and that YopJ plays a predominant role in this inhibition.

\subsection{Yersinia pCD1-encoded factors actively inhibit IL-8 secretion by PMNs}

Because the most abundant cytokine secreted by human PMNs within $12 \mathrm{~h}$ of incubation with $Y$. pestis KIM6 was IL-8, we performed specific ELISA assays to further characterize the apparent pCD1-dependent inhibition of IL-8 secretion. First, we ascertained whether factors encoded in the 102-kb chromosomal Pgm locus or on pCD1 other than the major effector proteins were involved in the ability of KIM5 to inhibit secretion of IL-8. PMNs were incubated with KIM6+, which unlike KIM5 and KIM6 contains a wild-type Pgm locus [18], and KIM6+ transformed with the plasmid $\mathrm{pCD} 1 \Delta 1234$. This plasmid is a deletion derivative of pCD1 that lacks the genes for the major effector proteins YopE, YopH, YopT, YopJ, YopM and YpkA but still encodes the proteins necessary for assembly of a functional T3SS [19]. Incubation of either KIM6+ or KIM6+ (pCD1 $\Delta 1234)$ with PMNs resulted in high levels of IL-8, equivalent to levels resulting from incubation of PMNs with KIM6 (Fig. 2). Therefore, $Y$. pestis inhibition of IL-8 secretion by PMNs requires the major effector proteins encoded on $\mathrm{pCD} 1$ and factors not encoded on $\mathrm{pCD} 1$ do not play a detectable role.

To assess if pCD1-dependent inhibition of IL-8 secretion was due to active suppression of cellular signaling or to a lack of stimulation, PMNs were incubated with KIM5 prior to the addition of KIM6. Addition of KIM6 to PMNs that were preincubated with KIM5 did not induce secretion of IL-8 (Fig. 2C; KIM5/KIM6). Furthermore, heat-inactivated KIM5 was no longer able to inhibit IL-8 secretion (Fig. 2C; H. I. KIM5). These results suggest that the greatly reduced level of IL-8 secretion observed after infection with $\mathrm{pCD} 1^{+} Y$. pestis is due to active suppression of cellular signaling and secretory pathways within the PMN, rather than to a lack of stimulation.

\subsection{YopJ of Y. pestis is a major factor involved in inhibition of IL-8 secretion by PMNs}

IL-8 secretion by PMNs following incubation with KIM5 was compared by ELISA to KIM5 strains lacking yopE, yopH, yopT, yopJ, yopM, or ypkA. In keeping with results from the multiplex bead array (Fig. 1), KIM5 inhibited IL-8 secretion by PMNs, and incubation of PMNs with KIM5 $\triangle y o p J$ resulted in an intermediate level of IL-8 secretion (Fig. 3A and B). Complementation of the KIM5 $\Delta y o p J$ strain with low- or high-copy number plasmids containing yopJ and its native promoter (pWKS::yopJ and pCR::yopJ, respectively) restored IL-8 suppression to levels seen following incubation of PMNs with parental KIM5 (Fig. 3A and B). Complementation plasmids were also transformed into KIM6 (pCD1 $\Delta 1234)$ to determine if expression of YopJ in the absence of the other effector Yop proteins was sufficient for inhibition of IL-8 secretion by PMNs. KIM6 (pCD1 $\Delta 1234$ ) containing the high-copy number pCR::yopJ was able to partially inhibit IL-8 secretion by PMNs, but IL-8 
levels were about 10-fold higher than seen after infection with KIM5. Transformation of KIM6 (pCD1 1234 ) with the low-copy number plasmid pWKS::yopJ, however, was not sufficient to inhibit IL-8 secretion at all (Fig. 3A and B). As expected, transformation of KIM6, which completely lacks the T3SS, with pWKS::yopJ or pCR::yopJ had no effect. Taken together, these results indicate that YopJ is the major effector protein responsible for suppressing IL-8 production by PMNs. Complementation in trans was dependent on yopJ copy number, however, suggesting that other Yop effectors participate in IL-8 pathway inhibition.

\subsection{Opsonization of Yersinia does not alter IL-8 secretion and YopJ/P of the enteropathogenic Yersinia also inhibits IL-8 secretion by PMNs}

To determine if opsonization of $Y$. pestis alters IL-8 secretion by PMNs, unopsonized KIM5 and KIM6 were incubated with human PMNs. Unopsonized KIM6 stimulated equivalent levels of IL-8 secretion by PMNs (Fig. 4) as KIM6 that had been opsonized (Fig. 2 and 3). In addition, unopsonized KIM5 (Fig. 4) inhibited IL-8 secretion similarly to unopsonized KIM5 (Fig. 2 and 3). Since opsonization did not alter IL-8 secretion or inhibition and because enteropathogenic $Y$. enterocolitica is relatively more susceptible to killing by complement components from human serum than $Y$. pestis [20,21], experiments comparing $Y$. pestis to the enteropathogenic strains were performed using unopsonized bacteria. Wildtype (virulence plasmid-positive) $Y$. enterocolitica and $Y$. pseudotuberculosis were both able to inhibit IL-8 secretion by PMNs as well as Y. pestis KIM5 (Fig. 4). In contrast, high levels of IL-8 were secreted by PMNs within $12 \mathrm{~h}$ after infection with the two enteropathogenic Yersinia species that had been cured of their virulence plasmid $\left(\mathrm{pYV}^{-}\right)$, similar to levels produced by PMNs incubated with the $\mathrm{pCD1}^{-}$Y. pestis KIM6 (Fig. 4). A Y. pestis KIM5 strain in which the native yopJ on $\mathrm{pCD} 1$ had been replaced with the $y o p P$ gene from $Y$. enterocolitica inhibited IL-8 secretion to the same degree as the parental KIM5 strain (Fig. 4). Thus, IL-8 secretion by PMNs was similarly suppressed by the virulence plasmidencoded T3SS of all three pathogenic Yersinia, independent of opsonization, and YopJ and YopP were equally capable of producing this inhibition.

\section{Discussion}

A delayed PMN response to $Y$. pestis infection correlates strongly with disease progression and virulence. In bubonic plague models, large numbers of PMNs respond to $Y$. pestis immediately after intradermal transmission [5]. Following this initial encounter at the dermal infection site, however, subsequent PMN recruitment to either the dermal infection site or the infected lymph node is not sustained in animals infected with wild-type $Y$. pestis [6-10]. Essential $Y$. pestis virulence factors including the virulence plasmid and the Ail outer membrane protein have been implicated in the delayed PMN response in the developing bubo, which is strongly correlated with virulence [8-10]. In sharp contrast to wild-type $Y$. pestis, intradermal infection with $\mathrm{pCD1}^{-}$or $\Delta$ ail Y. pestis strains results in marked recruitment of PMNs to the draining lymph node and resolution of the infection [8-10]. Thus, an ability to limit PMN recruitment to the infected lymph node appears to be a pivotal aspect of the anti-innate immunity pathogenesis strategy of $Y$. pestis. 
Translocation of one or more of the virulence plasmid-encoded Yop effector proteins into human and murine PMNs has been shown to inhibit phagocytosis and ROS production and to alter apoptosis [15,22-25], and in vivo studies have noted that PMNs are a primary target cell for the $Y$. pestis T3SS [26,27]. Although most $Y$. pestis are killed following phagocytosis by PMNs, in vitro studies have shown that a certain percentage survives, and that this resistance is independent of the virulence plasmid [28]. Motivated by the fact that PMNs are not only efficient phagocytic cells capable of directly eliminating most invading pathogens but are also sources of cytokines and chemokines important for mediating the innate and adaptive immune response [2,3], we evaluated cytokine production by human PMNs incubated with $Y$. pestis. The most notable finding was that the $\mathrm{pCD} 1^{+} \mathrm{KIM} 5$ strain completely suppressed secretion of the proinflammatory chemokine IL-8, whereas extremely high levels $\left(\sim 10^{4} \mathrm{pg} / \mathrm{ml}\right)$ of IL- 8 were secreted by PMNs incubated with the pCD1- KIM6 strain. IL-8 (CXCL8) is rapidly produced and secreted in large amounts ( $\mathrm{ng} / \mathrm{ml}$ as opposed to $\mathrm{pg} / \mathrm{ml}$ for most other cytokines) by human PMNs upon exposure to a foreign particle or an appropriate ligand [29]. IL-8 is also a key mediator for the recruitment of circulating PMNs to an infection site, because PMNs are also the primary target for this chemokine, to which they respond by chemotaxis, increased transmigration across endothelial barriers, release of granule enzymes, and respiratory burst [29]. Thus, suppression of IL-8 secretion by wild-type $Y$. pestis may be one reason for the limited PMN response in the developing bubo. The full effect of $Y$. pestis on IL-8 secretion occurred by the $12 \mathrm{~h}$ timepoint, indicating that it was not due to a delay in cytokine production but rather to rapid and permanent inhibition.

In the initial screen, other cytokines besides IL- 8 were secreted at higher levels by PMNs incubated with $\mathrm{pCD}^{-}$Y. pestis or E. coli than with $\mathrm{pCD} 1^{+}$Y. pestis (Fig. 1). Compared to IL-8, however, the increased secretion was modest and was not detected in all of the donor samples. It is somewhat controversial as to which specific cytokines are produced by PMNs in response to different stimuli. A complicating factor is that small numbers of contaminating lymphocytes and monocytes in PMN preparations can produce the same cytokines, often in greater amounts than PMNs on a per-cell basis [2,3]. We did not detect large quantities of IL-6, IL-1 $\beta$, TNF-a, IL-12 or GM-CSF in our assay, and it is possible that some were produced by the $<1 \%$ of contaminating lymphocytes or peripheral blood mononuclear cells (PBMCs) in our PMN preparations. In contrast to the other cytokines we screened, the release of large amounts of IL-8 is a well-established response of human PMNs to infection stimuli [29].

The contribution of each of the six known effector Yop proteins to the observed pCD1dependent inhibition of IL-8 secretion was evaluated by incubating PMNs with individual Yop deletion mutant strains. We did not observe any differences in cytokine production by human PMNs incubated with the parental KIM5 strain or the yopE, $-H,-T,-M$ or $y p k A / y o p O$ mutants. Only the $\triangle y o p J$ mutant was significantly less inhibitory than KIM5, indicating that YopJ is the major effector involved in suppressing IL-8 production by PMNs. YopJ/P has previously been shown to specifically suppress IL-8 production by epithelial cells, [30,31], HeLa and HEK293 cells [32,33], and umbilical vein endothelial cells [34]. In addition to 
YopJ/P, YopE, $-\mathrm{H}$ and $-\mathrm{T}$ have all been found to counteract production of IL-8 by epithelial cells and HeLa cells $[30,35,36]$.

IL-8 levels secreted by PMNs incubated with the $\triangle y o p J$ mutant, although 10-fold higher than seen with the parental KIM5 strain, were still at least 2-fold lower than for $\mathrm{pCD}^{-} Y$. pestis. KIM6 (pCD1 1234 ) (pCR::yopJ) was able to inhibit IL-8 secretion more so than KIM6 (pCD1 1 1234) (pWKS::yopJ), suggesting that inhibition is dependent in part on the amount of YopJ translocated into PMNs. In addition, whereas KIM5 4 yopJ complemented with YopJ expressed from either a low-copy (pWKS::yopJ) or high-copy (pCR::yopJ) plasmid was fully able to inhibit IL-8 secretion; KIM6 (pCD1 1 1234) (pWKS::yopJ) and KIM6 (pCD1 1234 ) (pCR::yopJ) were not able to inhibit IL-8 secretion as much as KIM5. Together, these results suggest that YopJ alone is not sufficient for the observed pCD1dependent complete inhibition of IL-8 secretion by human PMNs and that the other effector proteins likely potentiate YopJ-mediated inhibition and aid in disruption of PMN signaling pathways leading to IL-8 production. For example, YopH of Y. pseudotuberculosis has been shown to confer in vivo resistance to murine PMNs by disrupting signaling pathways [37]. It is noteworthy that YopJ was also the only individual effector required for suppression of all of the other cytokines secreted at elevated levels when exposed to the $\mathrm{pCD}^{-} \mathrm{KIM} 6$ strain (Fig. 1), suggesting that YopJ is the most active T3SS effector against PMNs in general.

Because the T3SS has known antiphagocytic effects, decreased uptake of $\mathrm{pCD} 1^{+} Y$. pestis and a potentially decreased stimulation of the IL-8 synthesis pathway may account in part for our results. However, in the experimental conditions we used, PMNs rapidly phagocytize both $\mathrm{pCD} 1^{+}$and $\mathrm{pCD} 1^{-} Y$. pestis, with only about a 2 -fold final difference in relative internalization [22]. Furthermore, no differences in phagocytosis by PMNs were observed between KIM5 and KIM5 $\Delta y o p J$, consistent with previous findings that YopH, -T, and -O, but not the YopJ homolog YopP, inhibit phagocytosis of $Y$. enterocolitica by human PMNs [24]. The most abundant cytokine secreted by human PMNs in response to infection with $Y$. pestis $\mathrm{KIM} 6$ was IL-8, and $\mathrm{pCD} 1^{+} Y$. pestis, particularly YopJ encoded on $\mathrm{pCD} 1$, was able to inhibit secretion of IL-8. This suggests that, similar to previous studies, differences in IL-8 production were not primarily due to differences in phagocytosis [32]. The previously described ability of YopJ/P to effectively inhibit both the MAPK and NFkB pathways [33] is a likely mechanism for inhibition of IL-8 secretion by human PMNs.

We also observed that IL-8 is highly produced by PMNs following incubation with the enteropathogenic Yersinia species lacking $\mathrm{pYV}$, and that $\mathrm{pYV}^{+}$strains inhibited IL-8 secretion. Arnold and König previously reported that $Y$. enterocolitica exhibits a pYVdependent suppression of IL-8 production by human PMNs [38]. Furthermore, $\mathrm{pYV}^{+} Y$. enterocolitica and $Y$. pseudotuberculosis inhibited IL-8 production similarly to $\mathrm{pCD} 1^{+} Y$. pestis. Our data indicate that expression of YopP either by $Y$. enterocolitica or in place of YopJ by Y. pestis (yopJ-yopP strain, Fig. 2C) cause equivalent inhibition of IL-8 secretion by PMNs.

In conclusion, pathogenic Yersinia species are able to inhibit production of the proinflammatory cytokine IL- 8 by human PMNs and virulence plasmid-encoded factors, particularly YopJ/P, are necessary for this inhibition. Inhibition of IL-8, a potent 
chemoattractant for PMNs, and other proinflammatory cytokines could be important for Yersinia disease progression by limiting the recruitment and accumulation of neutrophils and other immune cells. In mice and rats, infection with $\mathrm{pCD}^{-} Y$. pestis results in increased PMN recruitment and accumulation in the lymph node relative to $\mathrm{pCD}^{+} Y$. pestis $[8,10]$. YopJ is not essential for Yersinia pathogenesis in these murine models [13,39]; however, YopJ was found to be a virulence factor important for $Y$. pseudotuberculosis to establish a systemic infection [40] and for $Y$. enterocolitica persistence within the spleen [41]. As suggested by our findings, other effector proteins may compensate for the loss of YopJ to some extent, thus explaining a lack of an essential role for YopJ in disease progression in murine plague models. Alternatively, many differences between human and murine PMNs exist, notably the fact that murine PMNs do not produce IL- 8 but rather the functional IL- 8 homologs KC, MIP-2 and LIX. Since YopJ has such a dramatic inhibitory effect on IL-8 production by human PMNs, it is possible that YopJ plays a greater role in limiting a PMN response to Yersinia in humans than it does in murine models.

\section{Acknowledgements}

This research was supported by the Division of Intramural Research, NIAID, NIH. We thank Frank DeLeo, Addie Porter and Brett Freedman for providing isolated human PMNs and blood samples. We thank Kim Hasenkrug, Natalia Malachowa, and Chris Bosio for critical review of the manuscript.

\section{References}

1. Kolaczkowska E, Kubes P. Neutrophil recruitment and function in health and inflammation. Nat Rev Immunol. 2013; 13:159-175. [PubMed: 23435331]

2. Jaillon S, Galdiero MR, Del Prete D, Cassatella MA, Garlanda C, Mantovani A. Neutrophils in innate and adaptive immunity. Semin Immunopathol. 2013; 35:377-394. [PubMed: 23553214]

3. Mantovani A, Cassatella MA, Costantini C, Jaillon S. Neutrophils in the activation and regulation of innate and adaptive immunity. Nat Rev Immunol. 2011; 11:519-531. [PubMed: 21785456]

4. Viboud GI, Bliska JB. Yersinia outer proteins: role in modulation of host cell signaling responses and pathogenesis. Ann Rev Microbiol. 2005; 59:69-89. [PubMed: 15847602]

5. Shannon JG, Hasenkrug AM, Dorward DW, Nair V, Carmody AB, Hinnebusch BJ. Yersinia pestis subverts the dermal neutrophil response in a mouse model of bubonic plague. MBio. 2013; 4:e00170-e00113. [PubMed: 23982068]

6. Sebbane F, Gardner D, Long D, Gowen BB, Hinnebusch BJ. Kinetics of disease progression and host response in a rat model of bubonic plague. Am J Pathol. 2005; 166:1427-1439. [PubMed: 15855643]

7. Guinet F, Ave P, Jones L, Huerre M, Carniel E. Defective innate cell response and lymph node infiltration specify Yersinia pestis infection. PLoS One. 2008; 3:e1688. [PubMed: 18301765]

8. Comer JE, Sturdevant DE, Carmody AB, Virtaneva K, Gardner D, Long D, et al. Transcriptomic and innate immune responses to Yersinia pestis in the lymph node during bubonic plague. Infect Immun. 2010; 78:5086-5098. [PubMed: 20876291]

9. Hinnebusch BJ, Jarrett CO, Callison JA, Gardner D, Buchanan SK, Plano GV. Role of the Yersinia pestis Ail protein in preventing a protective polymorphonuclear leukocyte response during bubonic plague. Infect Immun. 2011; 79:4984-4989. [PubMed: 21969002]

10. Bosio CF, Jarrett CO, Gardner D, Hinnebusch BJ. Kinetics of innate immune response to Yersinia pestis after intradermal infection in a mouse model. Infect Immun. 2012; 80:4034-4045. [PubMed: 22966041]

11. Cantwell AM, Bubeck SS, Dube PH. YopH inhibits early pro-inflammatory cytokine responses during plague pneumonia. BMC Immunol. 2010; 1:29. [PubMed: 20565713] 
12. Brubaker RR. Interleukin-10 and inhibition of innate immunity to Yersiniae: roles of Yops and LcrV (V antigen). Infect Immun. 2003; 71:3673-3681. [PubMed: 12819047]

13. Lemaitre N, Sebbane F, Long D, Hinnebusch BJ. Yersinia pestis YopJ suppresses tumor necrosis factor alpha induction and contributes to apoptosis of immune cells in the lymph node but is not requried for virulence in a rat model of bubonic plague. Infect Immun. 2006; 74:5126-5131. [PubMed: 16926404]

14. Datsenko KA, Wanner BL. One-step inactivation of chromosomal genes in Escherichia coli K-12 using PCR products. Proc Natl Acad Sci USA. 2000; 97:6640-6645. [PubMed: 10829079]

15. Spinner JL, Seo KS, O'Loughlin JL, Cundiff JA, Minnich SA, Bohach GA, et al. Neutrophils are resistant to Yersinia YopJ/P-induced apoptosis and are protected from ROS-mediated cell death by the type III secretion system. PLoS One. 2010; 5:e9279. [PubMed: 20174624]

16. Riley G, Toma S. Detection of pathogenic Yersinia enterocolitica by using Congo red-magnesium oxalate agar medium. J Clin Microbiol. 1989; 27:213-214. [PubMed: 2913030]

17. Kobayashi SD, Voyich JM, Buhl CL, Stahl RM, DeLeo FR. Global changes in gene expression by human polymorphonuclear leukocytes during receptor-mediated phagocytosis: cell fate is regulated at the level of gene expression. Proc Natl Acad Sci USA. 2002; 99:6901-6906. [PubMed: 11983860]

18. Perry RD, Fetherston JD. Yersinia pestis - etiologic agent of plague. Clin Microbiol Rev. 1997; 10:35-66. [PubMed: 8993858]

19. Bartra SS, Jackson MW, Ross JA, Plano GV. Calcium-regulated Type III secretion of Yop proteins by an Escherichia coli hha mutant carrying a Yersinia pestis $\mathrm{pCD} 1$ virulence plasmid. Infect Immun. 2006; 74:1381-1386. [PubMed: 16428789]

20. Bartra SS, Styer KL, O'Bryant DM, Nilles ML, Hinnebusch BJ, Aballay A, et al. Resistance of Yersinia pestis to complement-dependent killing is mediated by the Ail outer membrane protein. Infect Immun. 2008; 76:612-622. [PubMed: 18025094]

21. Bliska JB, Falkow S. Bacterial resistance to complement killing mediated by the Ail protein of Yersinia enterocolitica. Proc Natl Acad Sci USA. 1992; 89:3561-3565. [PubMed: 1565652]

22. Spinner JL, Cundiff JA, Kobayashi SD. Yersinia pestis type III secretion system-dependent inhibition of human polymorphonuclear leukocyte function. Infect Immun. 2008; 76:3754-3760. [PubMed: 18490459]

23. Thorslund SE, Ermert D, Fahlgren A, Erttmann SF, Nilsson K, Hosseinzadeh A, et al. Role of YopK in Yersinia pseudotuberculosis resistance against polymorphonuclear leukocyte defense. Infect Immun. 2013; 81:11-22. [PubMed: 23090955]

24. Grosdent N, Maridonneau-Parini I, Sory M-P, Cornelis GR. Role of Yops and adhesins in resistance of Yersinia enterocolitica to phagocytosis. Infect Immun. 2002; 70:4165-4176. [PubMed: 12117925]

25. Ruckdeschel K, Roggenkamp A, Schubert S, Heesemann J. Differential contribution of Yersinia enterocolitica virulence factors to evasion of microbicidal action of neutrophils. Infect Immun. 1996; 64:724-733. [PubMed: 8641773]

26. Marketon MM, DePaolo RW, DeBord KL, Jabri B, Schneewind O. Plague bacteria target immune cells during infection. Science. 2005; 309:1739-1741. [PubMed: 16051750]

27. Pechous RD, Sivaraman V, Price PA, Stasulli NM, Goldman WE. Early host cell targets of Yersinia pestis during primary pneumonic plague. PLoS Pathog. 2013; 9:e1003679. [PubMed: 24098126]

28. Spinner JL, Winfree S, Starr T, Shannon JG, Nair V, Steele-Mortimer O, et al. Yersinia pestis survival and replication within human neutrophil phagosomes and uptake of infected neutrophils by macrophages. J Leukoc Biol. 2014; 95:389-398. [PubMed: 24227798]

29. Cassatella MA. Neutrophil-derived proteins: selling cytokines by the pound. Adv Immunol. 1999; 73:369-509. [PubMed: 10399011]

30. Bose R, Thinwa J, Chaparro P, Zhong Y, Bose S, Zhong G, et al. Mitogen-activated protein kinase-dependent interleukin-1alpha intracrine signaling is modulated by YopP during Yersinia enterocolitica infection. Infect Immun. 2012; 80:289-297. [PubMed: 22083707] 
31. Zhou L, Tan A, Hershenson MB. Yersinia YopJ inhibits pro-inflammatory molecule expression in human bronchial epithelial cells. Respir Physiol Neurobiol. 2004; 140:89-97. [PubMed: 15109931]

32. Schesser K, Spiik AK, Dukuzumuremyi JM, Neurath MF, Pettersson S, Wolf-Watz H. The yopJ locus is required for Yersinia-mediated inhibition of NF-kappaB activation and cytokine expression: YopJ contains a eukaryotic SH2-like domain that is essential for its repressive activity. Mol Microbiol. 1998; 28:1067-1079. [PubMed: 9680199]

33. Sweet CR, Conlon J, Golenbock DT, Goguen J, Silverman N. YopJ targets TRAF proteins to inhibit TLR-mediated NF-kappaB, MAPK and IRF3 signal transduction. Cell Microbiol. 2007; 9:2700-2715. [PubMed: 17608743]

34. Denecker G, Totemeyer S, Mota LJ, Troisfontaines P, Lambermont I, Youta C, et al. Effect of lowand high-virulence Yersinia enterocolitica strains on the inflammatory response of human umbilical vein endothelial cells. Infect Immun. 2002; 70:3510-3520. [PubMed: 12065490]

35. Viboud GI, Mejia E, Bliska JB. Comparison of YopE and YopT activities in counteracting host signalling responses to Yersinia pseudotuberculosis infection. Cell Microbiol. 2006; 8:1504-1515. [PubMed: 16922868]

36. Viboud GI, So SS, Ryndak MB, Bliska JB. Proinflammatory signalling stimulated by the type III translocation factor YopB is counteracted by multiple effectors in epithelial cells infected with Yersinia pseudotuberculosis. Mol Microbiol. 2003; 47:1305-1315. [PubMed: 12603736]

37. Rolán HG, Durand EA, Mecsas J. Identifying Yersinia YopH-targeted signal transduction pathways that impair neutrophil responses during in vivo murine infection. Cell Host Microbe. 2013; 14:306-317. [PubMed: 24034616]

38. Arnold R, Konig W. Interleukin-8 release from human neutrophils after phagocytosis of Listeria monocytogenes and Yersinia enterocolitica. J Med Microbiol. 1998; 47:55-62. [PubMed: 9449950]

39. Zauberman A, Velan B, Mamroud E, Flashner Y, Shafferman A, Cohen S. Disparity between Yersinia pestis and Yersinia enterocolitica $\mathrm{O}: 8$ in YopJ/YopP-dependent functions. Adv Exp Med Biol. 2007; 603:312-320. [PubMed: 17966427]

40. Monack DM, Mecsas J, Bouley D, Falkow S. Yersinia -induced apoptosis in vivo aids in the establishment of a systemic infection of mice. J Exp Med. 1998; 188:2127-2137. [PubMed: 9841926]

41. Trülzsch K, Sporleder T, Igwe EI, Russmann H, Heesemann J. Contribution of the major secreted yops of Yersinia enterocolitica $\mathrm{O}: 8$ to pathogenicity in the mouse infection model. Infect Immun. 2004; 72:5227-5234. [PubMed: 15322017]

42. Whitfield C, Schoenhals G, Graham L. Mutants of Escherichia coli O9:K30 with altered synthesis and expression of the capsular K30 antigen. J Gen Microbiol. 1989; 135:2589-2599. [PubMed: 2698913]

43. Pepe JC, Badger JL, Miller VL. Growth phase and low $\mathrm{pH}$ affect the thermal regulation of the Yersinia enterocolitica inv gene. Mol Microbiol. 1994; 11:123-135. [PubMed: 7511772]

44. Chain PSG, Carniel E, Larimer FW, Lamerdin J, Stoutland PO, Regala WM, et al. Insights into the evolution of Yersinia pestis through whole-genome comparison with Yersinia pseudotuberculosis. Proc Natl Acad Sci USA. 2004; 101:13826-13831. [PubMed: 15358858] 

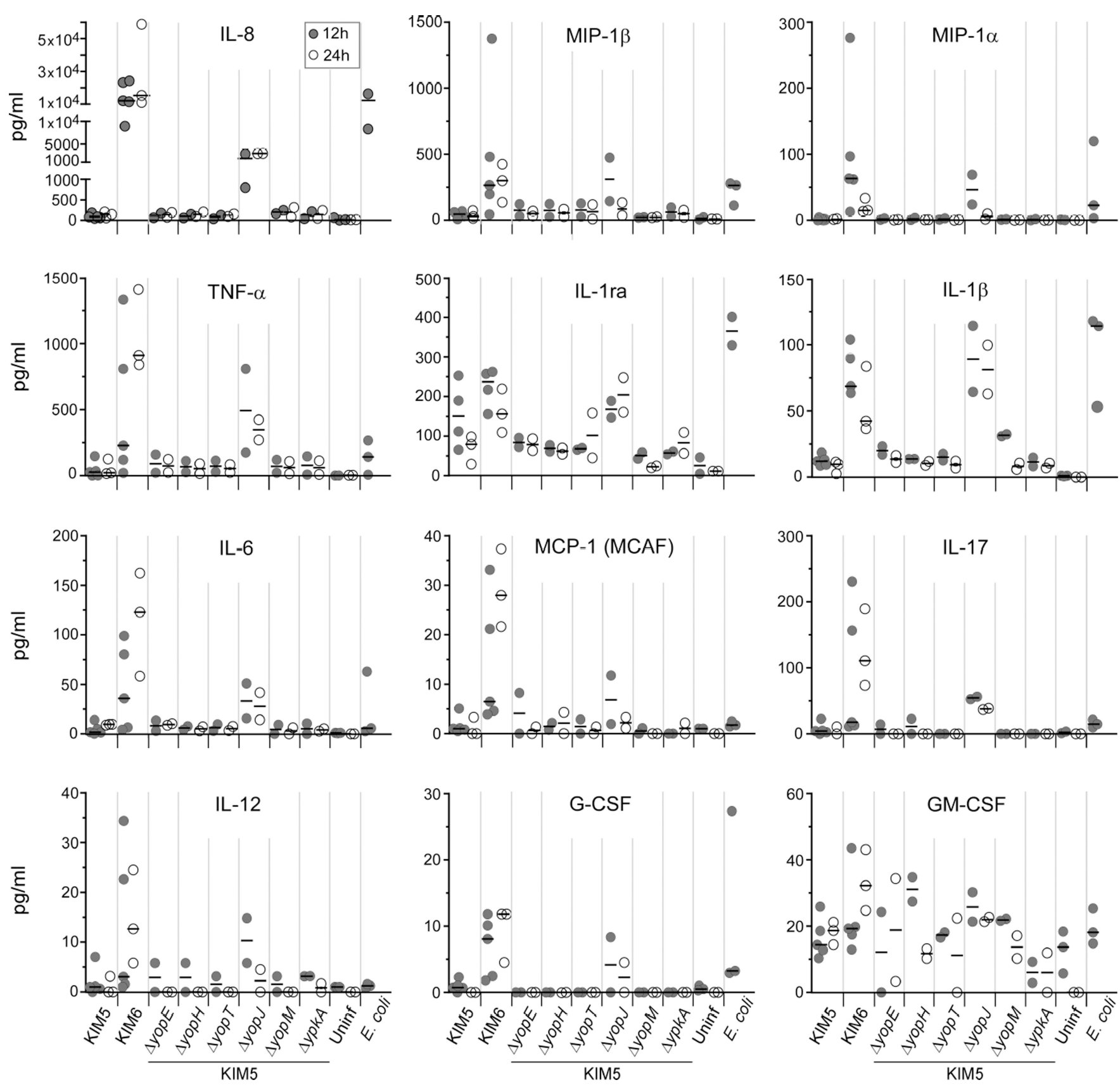

Fig. 1.

Y. pestis pCD1-dependent inhibition of cytokine secretion by human PMNs. Human PMNs were incubated with $E$. coli, $Y$. pestis KIM5 (pCD1 ${ }^{+}$), KIM6 (pCD1 ${ }^{-}$), or KIM5 mutant strains deleted of yopE, $-H,-T,-J,-M$ or $y p K A$. Uninfected PMNs served as unstimulated controls. Culture supernatant was collected after $12 \mathrm{~h}$ (gray circles) or $24 \mathrm{~h}$ (white circles) of incubation and assayed by multiplex bead arrays for the concentration of each indicated cytokine. The $24 \mathrm{~h}$ timepoint was not done for $E$. coli. Each circle represents the mean value of results from duplicate or triplicate wells of PMNs from a single donor; the horizontal line indicates the median of these values. 


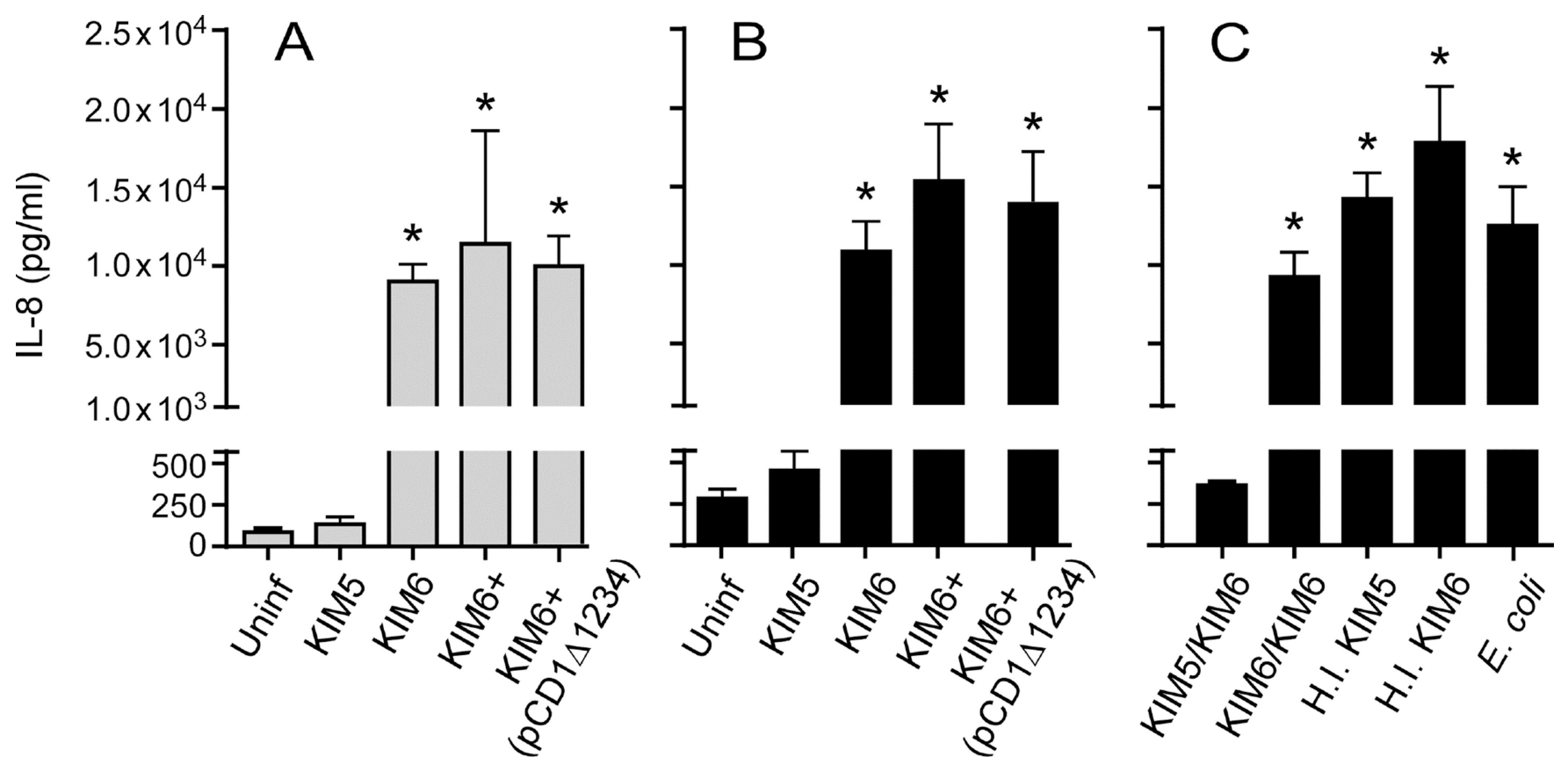

Fig. 2.

$Y$. pestis pCD1-dependent inhibition of IL-8 requires the effector Yop proteins. IL-8 secreted by human PMNs following incubation with $Y$. pestis containing the wild-type pCD1 virulence plasmid (KIM5), pCD1 ${ }^{-} Y$. pestis with (KIM6+) or without (KIM6) the chromosomal Pgm locus, or with KIM6+ transformed with pCD1 $\Delta 1234$ (which lacks the six effector Yop genes but encodes the genes necessary for the T3SS) were compared (A, B). Alternatively, PMNs were incubated with KIM5 or KIM6 prior to the addition of KIM6 (KIM5/KIM6 and KIM6/KIM6, respectively) or with heat inactivated (H.I.) KIM5 or KIM6 (C). PMNs incubated alone or with $E$. coli were included as controls. Culture supernatant was collected after $12 \mathrm{~h}(\mathrm{~A})$ or $24 \mathrm{~h}(\mathrm{~B}, \mathrm{C})$ of incubation and the concentration of IL-8 was determined by ELISA. The mean and SEM for at least three independent experiments (except for H.I. KIM6 and E. coli, which were tested only twice) are indicated. Data were analyzed by one-way ANOVA with Tukey post-test. *, $P<0.05$ compared to KIM5. 

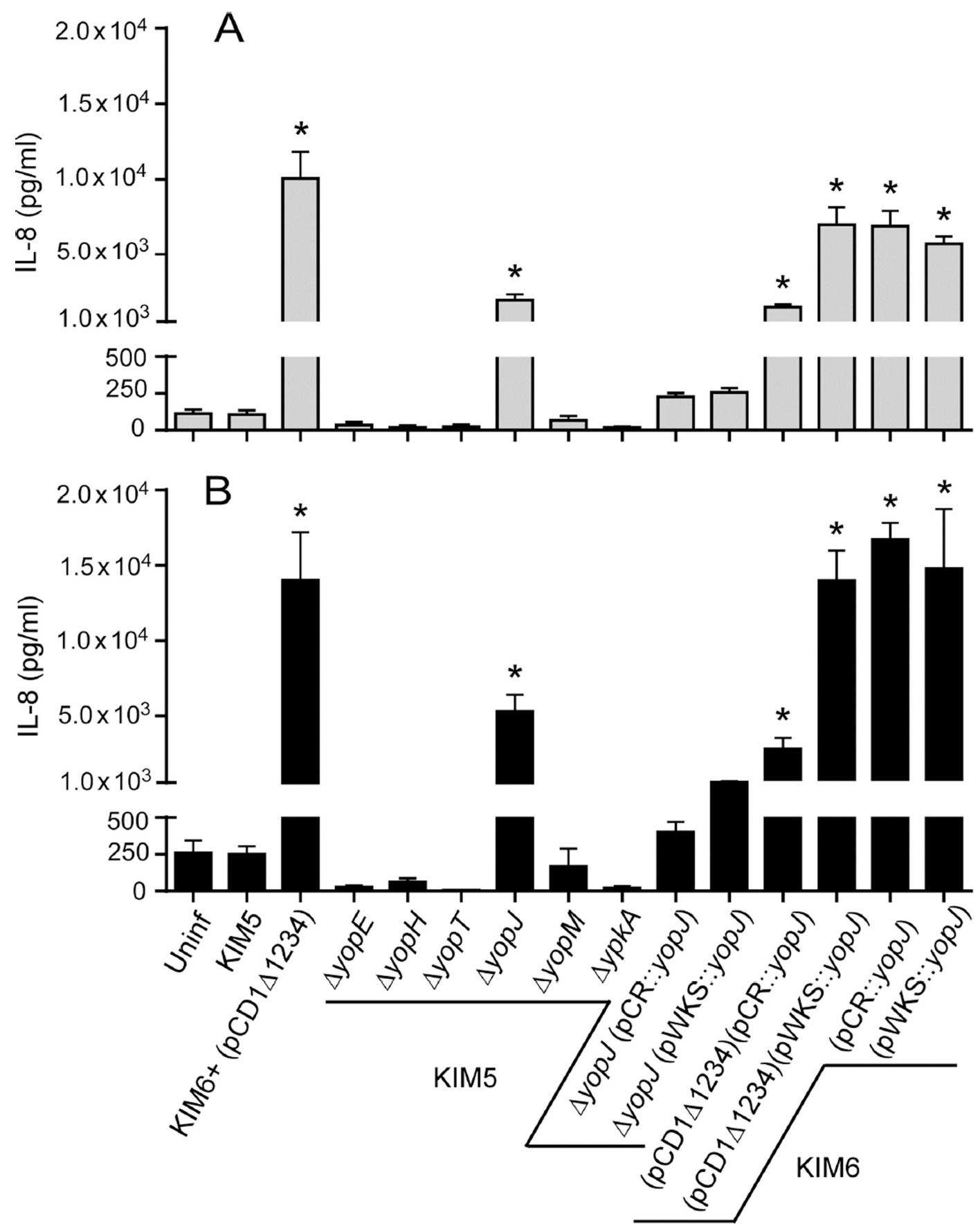

Fig. 3.

YopJ and the T3SS are required for $Y$. pestis inhibition of IL-8 secretion by PMNs. IL-8 secretion by human PMNs incubated with $Y$. pestis lacking yopE, $-H,-T,-J,-M$ or $y p K A$ was compared to PMNs incubated with the parental KIM5 or with KIM6+ (pCD1 1234). In addition, IL-8 secretion by PMNs incubated with the KIM5 4 yopJ or KIM6 strains that had been transformed with the low- or high-copy number complementation plasmids (pWKS::yopJ and PCR::yopJ, respectively) was determined. Culture supernatant was collected after $12 \mathrm{~h}$ (A) or $24 \mathrm{~h}$ (B) of incubation and the concentration of IL-8 was 
determined by ELISA. The mean and SEM for at least three independent experiments are indicated. Data were analyzed by one-way ANOVA with Tukey post-test. *, $P<0.05$ compared to KIM5. 


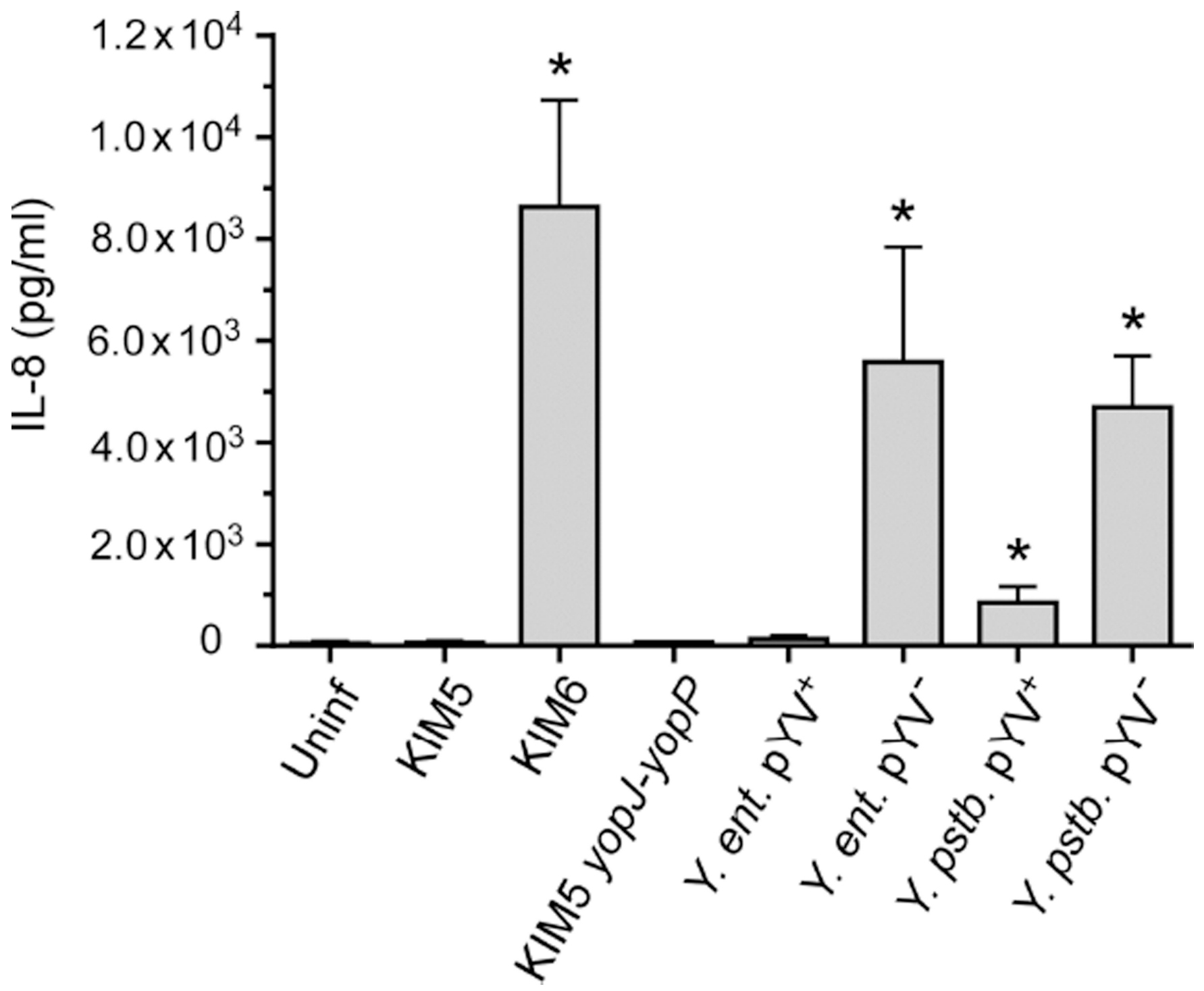

Fig. 4.

Virulence plasmid-dependent inhibition of IL-8 secretion by PMNs incubated with the enteropathogenic Yersinia species. Y. enterocolitica, (Y. ent.) and Y. pseudotuberculosis ( $Y$. pstb.) strains, with $\left(\mathrm{pYV}^{+}\right)$or without $\left(\mathrm{pYV}^{-}\right)$their native virulence plasmid were incubated with human PMNs and the amount of IL-8 secreted was compared to PMNs incubated with $\mathrm{pCD}^{+}$(KIM5) or $\mathrm{pCD}^{-}$(KIM6) Y. pestis. Y. pestis engineered to express yopP instead of yopJ (yopJ-yopP) was also incubated with PMNs. Culture supernatant was collected after 12 $\mathrm{h}$ of incubation and the concentration of IL- 8 was determined by ELISA. For these experiments the bacteria were not opsonized before addition to the PMNs. The mean and SEM for at least three independent experiments, except for the yopJ-yopP strain, for which only two experiments were realized, are indicated. Data were analyzed by one-way ANOVA with Tukey post-test. *, $P<0.05$ compared to KIM5. 


\section{Table 1}

Bacterial strains and plasmids used in this study

\begin{tabular}{|c|c|c|}
\hline Strain or Plasmid & Description ${ }^{a}$ & $\begin{array}{l}\text { Source or } \\
\text { reference }\end{array}$ \\
\hline \multicolumn{3}{|l|}{ Y. pestis strains } \\
\hline KIM6+ & pCD1-negative, Pgm $^{+}$ & [18] \\
\hline KIM6 & pCD1-negative, Pgm $^{-}$ & [18] \\
\hline KIM5 & pCD1-positive, $\mathrm{Pgm}^{-}$ & [18] \\
\hline KIM5 & yopJ deleted from $\mathrm{pCD} 1$ & [15] \\
\hline KIM5 уорJ-уорP & yopJ replaced with $Y$. enterocolitica yopP & [15] \\
\hline KIM5 4 уор E & yopE deleted from $\mathrm{pCD} 1$ & This study \\
\hline KIM5 $\Delta y о p H$ & yop $H$ deleted from $\mathrm{pCD} 1$ & This study \\
\hline KIM5 5 уор $T$ & yop $T$ deleted from $\mathrm{pCD} 1$ & This study \\
\hline KIM5 & yop $M$ deleted from $\mathrm{pCD} 1$ & This study \\
\hline KIM5 $4 y p k A$ & $y p k A$ deleted from $\mathrm{pCD} 1$ & This study \\
\hline KIM5 $5 y o p J(\mathrm{pWKS::yopJ)}$ & yopJ knockout with pWKS::yopJ (kan) & This study \\
\hline KIM5 4 yopJ (pCR::yopJ) & yopJ knockout with pCR::yopJ (kan) & This study \\
\hline KIM6 (pCD1 $\Delta 1234)$ & KIM6 with pCD1 $\Delta 1234$ (cam) & This study \\
\hline KIM6 (pCD1 1234$)(\mathrm{pWKS}:: y o p J)$ & KIM6 (pCD1 1234$)$ with pWKS::yopJ (cam, kan) & This study \\
\hline KIM6 (pCD1 $\Delta 1234)(\mathrm{pCR}:: y o p J)$ & KIM6 (pCD1 11234) with pCR::yopJ (cam, kan) & This study \\
\hline KIM6 (pWKS::yopJ) & KIM6 with pWKS::yopJ (kan) & This study \\
\hline KIM6 (pCR::yopJ) & KIM6 with pCR::yopJ (kan) & This study \\
\hline \multicolumn{3}{|l|}{ E. coli strains } \\
\hline E. coli & CWG28 (O9a/K30-) (str) & {$[42]$} \\
\hline \multicolumn{3}{|l|}{$\underline{Y . \text { enterocolitica strains }}$} \\
\hline Y. ent. $\mathrm{pYV}^{+}$ & 8081v, pYV-positive & {$[43]$} \\
\hline Y. ent. $\mathrm{pYV}^{-}$ & 8081c, pYV-negative & [43] \\
\hline \multicolumn{3}{|l|}{$\underline{\text { Y. pseudotuberculosis strains }}$} \\
\hline Y.pstb. $\mathrm{pYV}^{+}$ & IP32953, pYV-positive & [44] \\
\hline Y.pstb. $\mathrm{pYV}^{-}$ & IP32953, pYV-negative & [44] \\
\hline \multicolumn{3}{|l|}{ Plasmids } \\
\hline $\mathrm{pCD} 1 \Delta 1234$ & plasmid encoding the genes required for the T3SS, no effector Yops (cam) & [19] \\
\hline pCR::yopJ & $\begin{array}{l}\text { yopJ expressed under native promoter from the high-copy plasmid pCR-XL-Topo (kan, } \\
\text { zeo) }\end{array}$ & This study \\
\hline pWKS::уорJ & yopJ expressed under native promoter from the low-copy plasmid pWKS130 (kan) & This study \\
\hline
\end{tabular}




\section{Table 2}

Primers

\begin{tabular}{|c|c|}
\hline Primer Designation & Sequence ${ }^{a}$ \\
\hline yopJ complementation forward & 5'-AGTTGAGCTCCCCCTAAGCCTTGAGTTGATA-3' \\
\hline yopJ complementation reverse & 5'-AGTTTCTAGAGGATTGAGTTCCCTCAGTGAT-3' \\
\hline yopE knockout forward & 5'-ATGAAAATATCATCATTTATTTCTACATCACTGCCCGTGTAGGCTGGAGCTGCTTC-3' \\
\hline yopE knockout reverse & 5'-TCACATCAATGACAGTAATTTCTGCATCTGTTGCGCCATATGAATATCCTCCTTAG-3' \\
\hline yopH knockout forward & 5'-ATGAACTTATCATTAAGCGATCTTCATCGTCAGGTAGTGTAGGCTGGAGCTGCTTC-3' \\
\hline yopH knockout reverse & 5'-TTAGCTATTTAATAATGGTCGCCCTTGTCCTTCAGCCATATGAATATCCTCCTTAG-3' \\
\hline yopT knockout forward & 5'-ATGAACAGTATTCACGGACACTACCATATTCAACTAGTGTAGGCTGGAGCTGCTTC-3' \\
\hline yopT knockout reverse & 5'-TTAAACCTCCTTGGAGTCAAATGTTAACACTCTAAACATATGAATATCCTCCTTAG-3' \\
\hline yopM knockout forward & 5'-ATGTTCATAAATCCAAGAAATGTATCTAATACTTTTGTGTAGGCTGGAGCTGCTTC-3' \\
\hline yopM knockout reverse & 5'-CTACTCAAATACATCATCTTCAAGTTTGTCTGTAGTCATATGAATATCCTCCTTAG-3' \\
\hline$y p k A$ knockout forward & 5'-ATGAAAAGCGTGAAAATCATGGGAACTATGCCACCGGTGTAGGCTGGAGCTGCTTC-3' \\
\hline$y p k A$ knockout reverse & 5'-TCACATCCATTCCCGCTCCAACCGGTTCAGTCGCTCCATATGAATATCCTCCTTAG-3' \\
\hline
\end{tabular}

${ }^{a}$ Underlined sequence denotes restriction enzyme site addition 